\title{
Successful Medical Management of Caesarean Scar Ectopic Pregnancy-Case Report
}

\author{
Miss Bushra Iqbal, MBBS, MRCOG, Miss Khawla Aswad, Mr Sanjay Sinha, Department of Obstetrics \\ \& Gynaecology, Furness General Hospital, University Hospitals of Morecambe Bay NHS Trust
}

\section{INTRODUCTION}

Caesarean section (LSCS) scar pregnancy is one of the rarest forms of ectopic pregnancy which requires early diagnosis to prevent life threatening consequences. This is an interesting case report regarding medical management of caesarean scar ectopic pregnancy which was managed successfully with methotrexate despite very high $\beta$-hCG titres.

\section{CASE REPORT}

A 41 year old gravida 10 para 3+6 was seen in the gynaecology assessment unit. She presented with a 3 day history of slight lower abdominal pain and PV (per vaginal) spotting 6 weeks after her last menstrual period. Her pregnancy test was positive and an ultrasound was arranged for viability and to exclude an ectopic pregnancy. Her obstetric history included 3 previous caesarean sections, one termination of pregnancy and 5 early miscarriages. Her first 2 successful pregnancies were conceived through In vitro fertilization.

She was on progesterone only pills for contraception, but had regular monthly bleeds. She had undergone laparoscopy and laparotomy in the past for severe endometriosis and polycystic ovarian syndrome.

On admission her observations were normal. The abdomen was soft and non-tender. Speculum examination showed normal looking cervix and no bleeding. Her $\beta \mathrm{Hcg}$ level was $72,322 \mathrm{IU} / \mathrm{L}$ on admission. The ultrasound scan showed $19 \mathrm{~mm}$ irregular sac containing yolk sac, no fetal pole, protruding into previous caesarean section scar. The sac appeared to have breached the serosal margin of the myometrium.

A clinical diagnosis of a caesarean scar ectopic was made. The scan findings and treatment options (expectant, medical and surgical exploration) were discussed with the patient. She opted for medical management by methotrexate.

$92.5 \mathrm{mg}$ methotrexate was administered based on calculated dose according to $50 \mathrm{mg} / \mathrm{m} 2$. She was kept as an inpatient for a week due to the risk of rupture and subsequent haemorrhage, but she remained completely asymptomatic. $\beta \mathrm{Hcg}$ was repeated on day 7 but was found to be increased at $99111 \mathrm{IU} / \mathrm{L}$. She was given second dose of methotrexate owing to less than $15 \%$ drop from initial levels. She was readmitted with slight abdominal pain on day 9 . Her observations were stable.

Options were discussed again including local injection of methotrexate and hysteroscopic removal. The patient opted for expectant management with monitoring of $\beta$-hCG Levels.

Serial $\beta$-hCG levels every 48 hours were performed initially until levels dropped to < 25 IU/l. She stayed asymptomatic throughout. In the follow up she was advised to avoid pregnancy for 3 months due to teratogenic effect of methotrexate.

\section{DISCUSSION}

Caesarean section (LSCS) scar pregnancy is one of the rarest forms of ectopic pregnancy with an incidence quoted as approximately 1 in 1800-2000 pregnancies. ${ }^{1,2}$

There have been several case reports of caesarean scar ectopic pregnancy due to the rising incidence of caesarean section. Implantation occurs as a result of formation of tract between scar and endometrium canal due to previous trauma of caesarean section, dilation and curettage (D \& C), hysterotomy, myomectomy, abnormal placentation, assisted reproduction techniques and manual removal of placenta. ${ }^{3,4}$ Consequences of ruptured /undiagnosed scar ectopic can be associated with severe maternal morbidity and mortality due to complications of uterine rupture and haemorrhage that may require an urgent hysterectomy and blood transfusion, ${ }^{3}$ thus timely diagnosis and management is crucial which is challenging.

Bleeding and pain in early pregnancy are the most common signs at presentation. However, at the time of diagnosis during the first trimester, approximately one third of women are completely asymptomatic. ${ }^{5}$ Ultrasound aided with colour Doppler imaging plays a pivotal role in detecting all types of ectopic pregnancies, thus meticulous transvaginal evaluation of the anterior uterine wall, endometrial cavity and cervical canal should be performed in suspected cases in view of history and presentation. ${ }^{6}$ In equivocal cases magnetic resonance imaging (MRI) or laparoscopy may aid in diagnostic efficacy.

Management options should be on individual basis based on the size of the sac and gestational age, the severity of the patient's condition and her preference on having any future pregnancies. Options include expectant, medical and surgical. More than one of these management options may be required to successfully resolve the ectopic pregnancy.

Expectant management of a visible scar pregnancy is considered as potentially high risk for rupture, although successful cases have been observed. Despite inconclusiveness of ideal treatment modality for scar ectopic pregnancy, medical management with methotrexate can be considered as first line in selective group of women desiring conservation of fertility. ${ }^{7,8}$ In a subset of patients who do not respond to methotrexate but desire fertility there are successful cases treated with Uterine Artery Embolization9. Postulated reason of decreased response to methotrexate can be gestation at or beyond 9 weeks, embryonic cardiac activity $\beta$-hCG, level of $>$ or $=10,000$ $\mathrm{m} \mathrm{IU} / \mathrm{mL}$ and crown rump length of greater than $10 \mathrm{~mm} .{ }^{10}$

Surgical options include uterine curettage, laparoscopy and laparotomy particularly with high $\beta-\mathrm{hCG}$ and not responding to methotrexate. ${ }^{11}$

Post treatment surveillance should include serial clinical examinations, $\beta$-hCG measurements and repeat ultrasound examination as indicated.

For future pregnancies these women should seek medical advice early, due to chances of recurrences of ectopic pregnancies in caesarean scar, although very rare. ${ }^{12}$ 


\section{CONFLICTS OF INTERESTS}

None

\section{REFERENCES}

1. Jurkovic, D., Hillaby, K. \& Woelfer, B. et al. (2003) First-trimester diagnosis and management of pregnancies implanted into the lower uterine segment cesarean section scar, Ultrasound Obstet Gynecol, 21, pp. 220-7.

2. Fylstra, D.L., Pound-Chang, T. \& Miller, M.G. et al. (2002) Ectopic pregnancy within a caesarean delivery scar: a case report, Am 7 Obstet Gynecol, 87, pp. 302-4.

3. Ash, A., Smith, A. \& Maxwell, D. (2007) Caesarean scar pregnancy, B7OG 114, pp. 253-63.

4. Maymon, R., Halperin, R. \& Mendlovic, S. et al. (2004) Ectopic pregnancies in caesarean section scars: the 8 year experience of one medical center, Hum Reprod, 19, pp. 278-84.

5. Rotas, M., Haberman, S. \& Levgur, M. (2006) Cesarean scar ectopic pregnancies: etiology, diagnosis, and management, Obstet Gynecol, 107, pp. 1373-81.

6. Sieczko, D., Edwards, H. \& Heggs, K. et al. (2014) Caesarean scar ectopic pregnancy: a case report, Ultrasound, 22 pp. 126-28.
7. Ko, J.K., Li, R.H. \& Cheung, V.Y. (2015) Caesarean scar pregnancy: a 10-year experience, The Australian \& New Zealand Fournal of Obstetrics \& Gynaecology 55, pp. 64-69.

8. Hunt, S.P., Talmor, A. \& Vollenhoven, B. (2016) Management of non-tubal ectopic pregnancies at a large tertiary hospital, Reproductive Biomedicine Online, 33, pp. 79-84.

9. Zhou, Q., Young, D. \& Vingan, H. (2015) Uterine artery embolization for cervical ectopic pregnancy, Radiology Case Reports, 10, pp. 72-75.

10. Hung, T.H., Shau, W.Y. \& Hsieh, T.T. et al. (1998) Prognostic factors for an unsatisfactory primary methotrexate treatment of cervical pregnancy: a quantitative review, Hum Reprod, 13, pp. 2636-642.

11. Ades, A. \& Parghi, S. (2017) Laparoscopic resection of cesarean scar ectopic pregnancy, fournal of Minimally Invasive Gynecology, 24, pp. 533-35.

12. Ortiz, F., Angulo, B. \& Lapizco, B. et al. (2015) Repeated ectopic pregnancy in previous caesarean scar: a case report and literature review, Ginecologia y Obstetricia de Mexico, 83, pp. 641-647.

Correspondence to:

Dr Bushra Iqbal, Registrar in Obstetrics \& Gynaecology Furness General Hospital, iqbal.bushra@mbht.nhs.uk

\section{STOP PRESS !! Hospital team wins Brian Higson Trophy yet again}

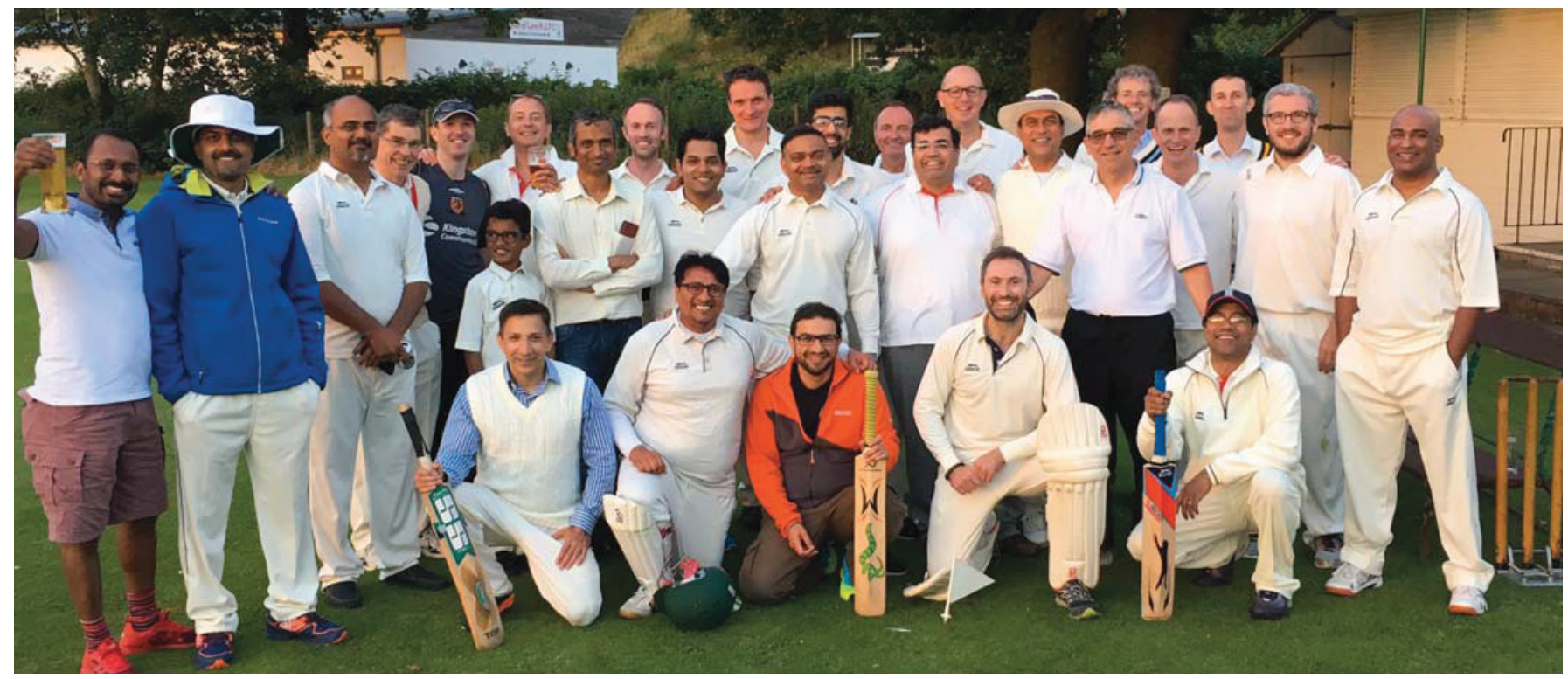

On a glorious evening in Bare in July, the historic sporting rivalry between the GP cricket team ably led by Cliff Elley and the Hospital team led for the first time by Kuntal Patel was renewed. The Hospital staff were so keen to play that the team was oversubscribed and 15 players had to be squeezed into the team. Past captain Chris Till arrived from the Isle of man stating that he had come over for a Graduation ceremony but we all knew that he had really come for the big match. He was drafted in to support the GP team. Despite this, the Hospital team got off to a flying start with Waqar Saadat and Vijay Gangalam piling on the runs. Bryan Rhodes came in at 3 and after a promising start was stumped by Nick Sayer going for a glory shot. A very solid score of 166 proved to be too much for the GP team despite a stylish knock by the evergreen Jeremy Marriott. The most exciting moment came when Lakshman had the GP team trembling with 2 wickets in successive balls and the hat-trick ball missed by a whisker! Things got a little confusing at the end as Don Magowan, who had bowled well for the Hospital team came out to bat for the GP team, and looked on course to transform their score only for the 20 overs to be completed. 